Ana Sofía Hernández Serrano 


\section{Símbolo y representación en el objeto común como arte}

\section{Introducción. Representación ₹ ¿aparición o apariencia?}

En la Antigüedad se consideró el arte como mímesis, es decir, como imitación. Platón fue quien añadió a este concepto una nueva definición que caracterizaba a un tipo concreto de arte y distinguió el arte que produce objetos del que simplemente los representa. Decía que el arte imita a la naturaleza, que era un espejo de la realidad, de la naturaleza. Inclusive desde su misma teoría de las ideas, el arte no era más que copia de la copia y, por tanto, sombra de la realidad verdadera, y por esto mismo no lo consideraba importante, pues la misma imitación se caracterizaba en términos de duplicar algo de algo que existía, y si se tenían las cosas en frente, para qué querría alguien tener una imitación de eso. ${ }^{1}$

Por otro lado, Aristóteles, en la Poética, nos dice que "los hombres disfrutan viendo imágenes, pues sucede que, contemplándolas, aprenden y deducen qué es cada cosa"2, es decir, los seres humanos disfrutan con las imitaciones, ya que obtienen placer cuando observan imágenes lo más verdaderas posibles. Así mismo, explica que la imitación se puede llevar a cabo de diferentes maneras, pues se puede imitar con diferentes medios, diferentes objetos o con diferentes modos. Y el modo en el que son imitados los objetos es lo que hace al arte. ${ }^{3}$

Ahora bien, existen dos tipos de tragedia: la primera es simple, en la cual la acción es continua y unitaria, pero no hay reconocimiento de ésta", entendiéndose reconocimiento como el "cambio

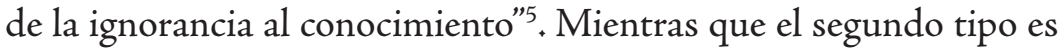

1 Platón, La República, libro X, Gredos, España, 1988, 601 c, p. 466.

2 Aristóteles, Poética, (trad. Salvador Mas), Colofón, México, 2001, p. 71.

3 Cfr. Ibidem p. 65.

4 Cfr. Ibidem p. 88.

5 Ibidem p. 89. 
la tragedia compleja, y en ésta sí se lleva a cabo el reconocimiento, pero también la peripecia, que es el "cambio del estado de cosas en dirección contraria" ${ }^{\prime}$, por lo que se podría decir que en la tragedia compleja hay un orden, un seguimiento, pues la trama o lo que acontece nace a partir de algo que ya había sucedido con anterioridad. Menciono esto porque pienso que también es factible para hablar de una obra de arte; la única diferencia es que la tragedia se lleva a cabo por medio del lenguaje, y en el arte, este reconocimiento de que habla Aristóteles, por medio de señales, por el recuerdo, pues al ver algo, comprendemos ${ }^{7}$. Así, el pintor imita cómo las cosas eran o son, cómo se supone que son o cómo deben ser ${ }^{8}$.

Pienso que es erróneo considerar al arte como una mera imitación del mundo o una imitación de los sentimientos humanos, pues creo que el artista no realiza una copia de su entorno, sino que lo representa, en el sentido de colocar semejanzas de algo en la mente, ser una muestra de u ocupar el lugar de algo.

$\mathrm{Al}$ decir que no es una mera imitación, me refiero al concepto de mímesis que planteó Platón, en el que el arte se consideró como una copia de la apariencia de las $\operatorname{cosas}^{9}$; no lo considero de tal modo pues para Platón el arte tenía o trataba de un ideal en el que se basaban los artistas, sin embargo, ese ideal no estaba en el mundo. Platón no aceptaba que el arte imitara la realidad, ya que la imitación no era el camino hacia la verdad, así pues, el arte era una copia de la copia del mundo ideal de lo inteligible.

Esta Vieja Teoría, como se le conoce, fue aceptada por mucho tiempo, con sus dos vertientes, a saber, la definición que le dio Platón y la de Aristóteles, y fue en la Edad Media cuando éstas tuvieron más auge, pues se pensaba que si el arte debía imitar, éste tendría que imitar al mundo invisible, y de no ser así, al menos debía buscar la belleza en el mundo visible ${ }^{10}$. Así pues, se buscaba que el artista plasmara lo bello como algo tal que nunca pareciera

6 Idem.

7 Cfr. Ibidem p. 103.

8 Cfr. Ibidem p. 126.

9 Cfr. Tatarkiewicz, Wladyslaw, Historia de seis ideas. Arte, belleza, forma, creatividad, mimesis, experiencia estética, Tecnos, 8va. Edición, España, 2015, p. 308 .

10 Cfr. Ibidem, p. 310. 
feo a nadie en ninguna parte ${ }^{11}$, pues se consideraba que al imitar al Creador, creaban un diseño mental de la mayor belleza ${ }^{12}$. Una vez más, se puede notar que se tienen los conceptos de arte y belleza basados en un ideal que no está en el mundo, entonces, ¿cómo saber si eso es lo verdadero si, de cierta manera, no se conoce?

Así pues, el arte representa al mundo, pues por medio de ésta no se tiene un ideal externo, que se base en algo que no está en el mundo, sino por el contrario, en algo mundano. Al representar las cosas se tiene una "libre interpretación de las cosas, sin pretender una escrupulosa fidelidad"13. El artista no fabrica lo real, sino algo semejante a lo real. El artista trabaja a partir de aquellos elementos que son propios de la mirada real del sujeto, así, el mundo se percibe desde la mirada que de él tenemos.

Por otro lado, las imitaciones pueden aludir a cosas falsas y representar cosas reales, por lo que considero importante mencionar el concepto de representación que manejan algunos autores.

Para Danto el concepto de representación tiene dos vertientes: la primera es representación en el sentido de que algo está en el lugar de otra cosa, y es en este tipo de representación donde se contrasta la apariencia con la realidad. El segundo tipo de representación consiste en que la cosa misma aparece ${ }^{14}$, por lo que representación aquí es entendida como un tipo de aparición, como una mímesis.

Así mismo, en la representación entendida como apariencia existen dos momentos o composiciones en la determinación acerca de la obra de arte, éstos son la referencialidad y la interpretación. La primera es la diferenciación, que hace alusión al contenido, es decir, de lo que trata la obra. Mientras que la interpretación es sobre qué se trata ${ }^{15}$.

11 Cfr. Platón, Hipias mayor, Gredos, España, 2010, p. 189.

12 Cfr. Tatarkiewicz, op. cit., p. 319.

13 Ibidem p. 317.

14 Cfr. Danto, Arthur. Transfiguración del lugar común (trad. Ángel y Aurora Mollá Román), Paidós, España, 2002, p. 46.

15 Cfr. Diapaola, Esteban, Ontología y estéticas post-representación: problemas de la filosofía del arte de Arthur Danto, Philosophia 71, 20011, p. 35. 


\section{Transfiguración del objeto común en obra de arte}

Como se dijo en el apartado anterior, el diseño de la obra de arte viene determinado por el significado que se pretende transmitir, sin embargo, ésta se halla plagada de elementos no dichos, que por medio del proceso de interpretación, de alguna manera, se dan a conocer. La interpretación no sólo implica una explicación de la obra, sino una forma de transfiguración, pues es ella la que transforma los objetos comunes en obra de arte $e^{16}$.

Transfiguración estética es el proceso por medio del cual el artista, y toda persona que vive una experiencia estética, elevan las imágenes a un nivel superior a su sentido habitual ${ }^{17}$, es decir, por medio de ésta, al objeto se le da una nueva significación, para que revele lo que en la percepción habitual se nos oculta.

Ahora bien, Duchamp fue el primero que llevó a cabo el transformar en obra de arte los objetos comunes, con el fin, tal vez, de demostrar que la belleza se puede encontrar en los lugares menos probables ${ }^{18}$. Con su primer ready-made, Rueda de bicicleta, instala esta nueva forma de producir arte, pues a partir de aquí se otorga la categoría de arte a objetos de consumo, de uso cotidiano. Así, ready-made se define como lo ya hecho, ya fabricado, pero recontextualizado; al recontextualizarlo se le da un nuevo significado, es decir, se saca un objeto cotidiano de su uso habitual para llevarlo a un uso estético. Las características de éstos se pueden resumir como: "Son obras que remiten a materiales sencillos; son objetos cotidianos; son desechables; no tienen gusto; son objetos neutros. Los ready-made, se determinan como un estilo no plástico" ${ }^{19}$.

Para Duchamp, el arte es concebido como un juego, como una adivinanza, y se requieren pistas para captar el sentido de la obra. No era arte para los sentidos, sino una máquina para pensar, por lo que se necesita la intervención del pensamiento. Una característica importante de la obra de este artista es que llevaba a cabo

16 Cfr. Vite, Edgar. Una reflexión filosófica sobre el arte después de su confusión con la realidad, ITAM, Estudios 87, vol. VI, 2008, p. 15.

17 Cfr. Ibidem p. 18.

18 Cfr. Danto, Arthur. Transfiguración del lugar común, op. cit., p. 14.

19 Licuime, Juan Alegría. Duchamp, el posmodernismo y la muerte del arte, Revista Crítica, Cl, 2006, consultado en: www.critica.cl/artes-visuales/ duchamp-el-posmodernismo-y-la-muerte-del-arte 
juegos de palabras y así guía la interpretación del espectador. $\mathrm{Mu}$ chas veces el título de la obra no tenía nada que ver con ésta, y al carecer de sentido y no guardar ninguna relación con la imagen visual, las palabras podían conducir a la mente por caminos impredecibles. Ahora bien, pienso que el éxito de un objeto artístico no depende completamente del artista, sino que está en gran medida atado a su contexto. Por ejemplo, a partir de la Caja Brillo, Danto puede mostrar que sólo en un contexto determinado, apelando a la teoría adecuada y bajo la interpretación correcta, algo tan ordinario como una caja de jabón puede transformarse en una obra de arte. Aquí también ocurre una transfiguración estética, pero en este caso es sobre un objeto común. ¿Por qué es una transfiguración? Porque, de alguna manera, permite mostrar que el arte ha dejado de interesarse por el aspecto exterior de las obras, que cualquier cosa puede ser arte. Ya no sólo vemos la Caja Brillo, sino un indicio del fin del arte. ${ }^{20}$

A partir de lo anterior, se plantea la pregunta ¿cuáles son las condiciones y características para denominar obra de arte a un objeto cualquiera?, y así mismo, surge el problema de discernir entre dos objetos que, en apariencia, son iguales.

\section{Problema de los indiscernibles}

A partir del surgimiento de las vanguardias, y más en específico del pop art con Andy Warhol y su Caja Brillo, nace una búsqueda de una definición del arte que tiene como objetivo establecer un criterio que permita dar cuenta de qué objetos son obras de arte y qué objetos no. Surge un problema que, a mi parecer, aún no se resuelve del todo, que consiste en la dificultad que se experimenta cuando se intenta diferenciar entre dos objetos que son perceptivamente iguales y que, sin embargo, son juzgados de diferente manera. Este problema es conocido como el problema de los indiscernibles.

20 Cfr. Scheck, Daniel Omar, La filosofía de Danto: un lugar común en la transfiguración de la bistoria y el arte, Páginas de Filosofía, Año XVI, No 19 (enero-julio 2015), Departamento de Filosofía, Universidad Nacional del Comahue, consultado en: http://revele.uncoma.edu.ar/htdoc/revele/ index.php/filosofia/index, p. 9. 
Por ejemplo, imaginemos que tenemos un objeto $\mathrm{X}$, el cual sabemos que es una obra de arte, pues es reconocida como tal, ya sea por críticos, artistas, personas aficionadas al arte, por museos, galerías, etcétera. Pero en casa tenemos un objeto Y, el cual es idéntico a $\mathrm{X}$, sin embargo, no es catalogado como arte, sino como un objeto común. ¿Cómo diferenciar esto de aquello?

Por ejemplo, un abrelatas que es una obra de arte y que, no obstante, es indiscernible de cualquier abrelatas que tenemos en casa. En dado caso, podríamos cambiarlo por su idéntica contraparte expuesta en el museo, y muy posiblemente nadie, ni siquiera los más expertos, notarán la diferencia. Pienso que la cuestión aquí es que los objetos pueden brincar del mundo del arte, es decir, ser considerados arte, y luego brincar al mundo real, sin peros ni cuestionamientos. Y si esto pasa, no podríamos decir si algo es arte o no.

¿Cómo es posible que de estos dos objetos que son indiscernibles, uno sea una obra de arte y el otro no? Probablemente porque uno tiene ciertas propiedades que son exclusivas de las obras de arte, pero me resulta un tanto absurdo que sólo un objeto de los dos tenga esas propiedades si son exactamente iguales.

Si pensamos el arte como lo que plantea el experimento de los indiscernibles, podemos darnos cuenta de que las obras de arte no pueden definirse en términos estrictamente perceptivos como la belleza, por dar un ejemplo. Por el contrario, las razones para que estos últimos cuadros no sean obras de arte mientras que sus gemelos indiscernibles sí lo sean, tienen que ver con el mundo del arte, el ser sobre algo, y encarnar un significado. ${ }^{21}$

\section{Conclusión. ¿Dónde están los límites del arte?}

$¿$ Nos dan cualquier cosa como arte y lo aceptamos para no parecer ignorantes? $\mathrm{O}$, ¿de verdad se puede discernir entre un objeto y una obra de arte? Para Danto, que el arte no pueda definirse en términos puramente perceptivos no significa que no sea posible definirlo en absoluto. De hecho, para que algo sea una obra de arte, y estoy de acuerdo con esto, debe tener un tema, es decir, ser sobre algo, ser

21 Cfr. Guzmán, Julián Eduardo. El problema de los indiscernibles: un análisis de la teoría de Arthur C. Danto, op. cit., p. 8. 
la representación de un objeto, en el primer sentido que se mencionó anteriormente, es decir, en el que algo está en lugar de otra cosa y por ello contrastamos la apariencia con la realidad. Así mismo, una obra de arte es algo que encarna aquello que representa, como en el segundo sentido que maneja del concepto de representación. Sí, todo está permitido, pero no todo va a ser visualizado como arte porque, sinceramente, considero que a veces no se está en el canal de posibilidades o de distribución. Un objeto común, por ejemplo, un abrelatas no puede llegar a ser arte, no porque no sea exhibido en un museo, sino porque no tiene una atmosfera histórico-teórica en la que se pueda reconocer como obra de arte.

Hacer obras de arte no consiste en poner o hacer objetos, aunque sean indiscernibles de otras obras de arte, que aparenten ser arte, sino en hacer objetos que digan algo no sólo al artista, sino a todos, y creo que lo más importante es que sean sobre algo, que hagan una declaración cargada de razones históricas y teóricas consistentes con el mundo del arte en el que la obra es producida. Posiblemente esas obras de arte no carezcan de sentido, simplemente por la época en la que fueron creadas, porque si un artista de la Edad Media hubiese considerado o expresado como obra de arte una cama o su propia orina, en esa época eso hubiese sido un insulto al arte.

El arte depende de su contexto histórico, social, político, pues sólo así se puede llegar a su comprensión. Por ejemplo, el surgimiento de las vanguardias se dio como un rechazo a lo tradicional: ya no se podía hacer arte de esa manera porque el contexto era diferente. Así, podemos arriesgarnos a decir que el arte es un elemento constitutivo de la sociedad, y que la explicación de su historia y de su naturaleza tiene que ver con el contexto del mismo ${ }^{22}$, y pienso que en eso radican los límites del arte.

22 Cfr. Páez, Andrés. El problema de la demarcación en estética: una crítica del criterio de Danto, op. cit., p. 147. 